\title{
Microtensile Bond Strength Evaluation of Composite Resin to Discolored Dentin After Amalgam Removal
}

\author{
Jyothi Mandava ${ }^{1}$, Sahithi Pamidimukkala ${ }^{1}$, Srujana Karumuri ${ }^{1}$, Ravichandra Ravi ${ }^{1}$, Roopesh Borugadda ${ }^{1}$ \\ , Abdul Afraaz ${ }^{1}$ \\ 1. Department of Conservative Dentistry and Endodontics, Gandhi Institute of Technology and Management (GITAM) \\ Dental College and Hospital, Visakhapatnam, IND
}

Corresponding author: Jyothi Mandava, jyothi10mandava@yahoo.in

\section{Abstract \\ Background}

To obtain prolonged clinical success with composite restorations, better bonding of resin to the tooth substrate is crucial.

\section{Aim}

The study was aimed to evaluate the microtensile bond strength ( $\mu$ TBS) of bulk-fill composite resin restorations when bonded to a cavity previously restored with amalgam, comparing with that of freshly prepared dentin.

\section{Materials and method}

Mesio-occlusal cavity preparations were done on 80 extracted human mandibular molars with a buccolingual width of $4 \mathrm{~mm}$ and a $1.5 \mathrm{~mm}$ axial depth by placing the gingival seat $0.5 \mathrm{~mm}$ coronal to the cementoenamel junction (CEJ) and were restored with fine-grain amalgam alloy. After thermocycling, the amalgam restorations were removed. Disto-occlusal cavities with similar dimensions of mesial cavities were prepared, and both the proximal surfaces were filled with bulk-fill composite using either etch-and-rinse or self-etch adhesives. Following thermomechanical cyclic loading, all the teeth were sectioned for $\mu$ TBS testing. Bond strength data expressed in megapascals (MPa) were subjected to statistical analyses using analysis of variance (ANOVA) and Tukey's multiple post-hoc tests.

\section{Results}

The total-etch adhesive exhibited statistically higher bond strength values to both dentin substrates compared to self-etch adhesives $(\mathrm{p}<0.05)$. Failure mode analysis reported more of adhesive failures.

Received 03/13/2020

Review began 03/22/2020 Review ended 04/01/2020 Published 04/04/2020

() Copyright 2020

Mandava et al. This is an open access article distributed under the terms of the Creative Commons Attribution License CC-BY 4.0., which permits unrestricted use, distribution, and reproduction in any medium, provided the original author and source are credited.

\section{Conclusion}

The $\mu$ TBS of bulk-fill composite resin restorations bonded to a cavity previously restored with amalgam was significantly lower than that of freshly prepared dentin. Total-etch adhesives bond strength was higher than self-etch adhesives to both the substrates tested.

\section{Categories: Dentistry}

Keywords: amalgam, bond strength, discolored dentin, self-etch adhesive, total-etch adhesive

\section{Introduction}

The use of composite resin materials through adhesive techniques is becoming a more popular procedure for replacing defective silver amalgam restorations. Achieving a reliable bond between the tooth substrate and composite resin is critical for better retention with minimal microleakage, which, in turn, results in the clinical longevity of the restoration. As dentin is more hydrophilic in nature, it is more difficult to obtain a durable bond of resin to dentin, whereas due to the presence of more inorganic components, it is easier to attain adequate bond with enamel.

Clinically, the dentin available beneath the previous amalgam restoration might have undergone changes like demineralization, remineralization, or sclerosis. Moreover, corrosion being the shortcoming of amalgam, over a period of time, deposits corrosive products at the interface, causing the discoloration of the underlying dentin [1]. This process, in turn, causes changes like reduced mineral volume, increased porosity of intertubular dentin, and degradation of collagen by host-mediated enzymes, all of which inevitably may have a negative impact on the performance of the adhesive bonding. Moreover, the permeability of discolored dentin decreases due to blockage of dentinal tubules with corrosive products, leading to reduced 
hybrid layer formation and inferior mechanical properties of the adhesive resin restorations [2-4].

The formation of hybridized dentin relies on the dentinal permeability and diffusion capacity of adhesive monomer into the demineralized dentin [5]. Among the two adhesive strategies that are most commonly performed, the etch-and-rinse (ER) procedure is characterized by a complex bonding procedure, whereas self-etching (SE) systems follow a trend towards simplification. Compared to etch-and-rinse, self-etch adhesives simultaneously demineralize and infiltrate, creating homogenous resin infiltration of collagen fibrils, reducing the variation between demineralization depth and infiltration of resin. Studies have reported better stability of the self-etch bonding system due to better protection of collagen fibrils with resin infiltration [6]. However, the efficacy of SE adhesives on enamel demineralization is uncertain. Clinically, very little evidence is available regarding the performance of different adhesives on the discolored dentin substrate.

Bonding stability of adhesive restorations can be evaluated in-vitro by thermo-mechanical cyclic aging procedures. Studies have shown that repetitive contraction, expansion, and mechanical loading stresses accelerate chemical degradation at the tooth-resin interface that can affect bond strength eventually [7-8]. The better a restoration resist the stresses imposed during polymerization and function, the stronger will be the adhesive bond [9].

Hence, this in-vitro study was aimed to investigate and compare the influence of thermo-mechanical stresses on the microtensile bond strength of etch-and-rinse and self-etch adhesives to discolored dentin after amalgam restoration removal. The hypotheses tested were (i) bond strengths of discolored and normal dentin are not dependent on the type of adhesive system used and (ii) thermo-mechanical cyclic aging procedures do not affect bonding effectiveness.

\section{Materials And Methods}

The study protocol was approved by the State Health University (D168601021) and ethical clearance was obtained from the institutional review board. Eighty human non-carious mandibular molar teeth having similar dimensions of buccolingual and mesiodistal widths were selected. The sample size was estimated using $\mathrm{G}$ power 3.1 software, and 40 samples were indicated as the minimum ideal size required with an alpha error probability of 0.05 . Collected teeth after disinfection in chloramine- $\mathrm{T}(0.5 \%)$ solution for two hours were stored in saline at $4^{\circ} \mathrm{C}$, maximum for three months before use. The sample mandibular molars were mounted in an auto-polymerizing resin with healthy teeth on each side to maintain the proper proximal contour and contacts. The root surfaces of teeth were covered with polyvinyl siloxane impression material for simulating the periodontal ligament. Teeth were stored at room temperature in distilled water throughout the experimental period.

\section{Restorative procedures}

Standardized class II mesio-occlusal cavities were prepared using a \# 245 tungsten carbide bur (SS White, New Jersey). A $90^{\circ}$ butt joint cavosurface margins were prepared with a $4 \mathrm{~mm}$ buccolingual width and 1.5 $\mathrm{mm}$ axial wall depth by placing the gingival seat $0.5 \mathrm{~mm}$ coronal to the cementoenamel junction (CEJ). After every five tooth preparations, a new bur was used. Following the tooth preparation, two coats of dental varnish (Deepti Dental Products of India Pvt. Ltd., Maharashtra, India) were applied, followed by the placement of the Tofflemire matrix band. Each cavity was then restored with fine-grain dental amalgam alloy (DPI, Maharashtra, India), followed by polishing of the restoration using fine-grit rubber abrasive points.

The amalgam-filled teeth were thermally stressed at $5^{\circ} \mathrm{C}$ and $55^{\circ} \mathrm{C}\left( \pm 1^{\circ} \mathrm{C}\right)$ for 10,000 cold and hot cycles with an immersion time of 30 seconds. This procedure was done to generate amalgam corrosion products and to simulate a year of restoration aging [10]. Following the thermocycling procedure, the amalgam restorations were removed from the mesio-occlusal cavities using a \# 4 round carbide burs (SS White, New Jersey) in a high-speed handpiece. The cavity preparation was extended to remove a $0.5 \mathrm{~mm}$ of discolored dentin under copious air and water coolant, to improve the adhesion of the substrate [11].

A disto-occlusal cavity with similar dimensions of the mesio-occlusal cavity was prepared on all teeth samples using \#245 carbide burs (SS White) with a high-speed handpiece. All the internal line angles were rounded. The sample teeth were grouped into two categories ( $\mathrm{n}=40$ each) based on the type of bonding procedure, i.e., the etch-and-rinse (ER) or self-etch (SE) adhesive system (Table 1), which were applied to enamel and dentin walls following the manufacturer's instructions. The Palodent sectional matrix system (Dentsply, New York) was used along with the BiTine separating ring (Dentsply) for restoring mesial and distal class II preparations. 


\section{Cureus}

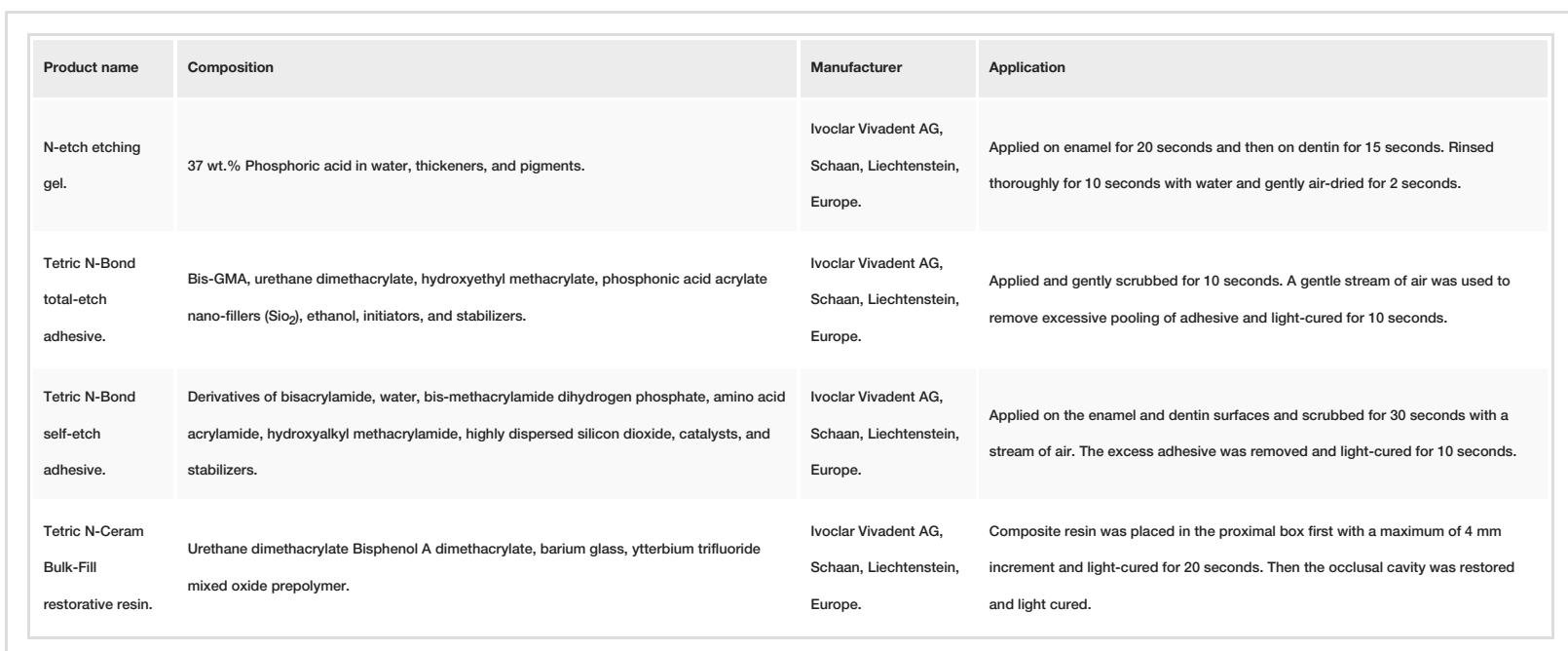

TABLE 1: Materials used in the study

A $4 \mathrm{~mm}$ thick increment of Tetric N-Ceram bulk-fill restorative resin (Ivoclar Vivadent AG, Liechtenstein, Europe) was placed in the prepared cavities and polymerized for 20 seconds using a Bluephase C8 lightemitting diode (LED) light-curing unit (Ivoclar Vivadent, Liechtenstein, Austria) with an intensity of 800 $\mathrm{mW} / \mathrm{cm}^{2}$. Finishing of composite restorations was done with fine-grit Sof-Lex flexible disks (3M ESPE, MN), and polishing was done using rubber cups (Shofu Dental Products, San Marcos) at low speed.

All the composite restored teeth were placed in water at room temperature for 24 hours and were subjected to a thermomechanical loading procedure to simulate clinical performance after the aging process. After thermocycling for 10,000 cycles, the teeth were submitted to $1,00,000$ cycles mechanically with an intermittent vertical occlusal loading of 50 Newtons at 20 cycles/minute. The axial force was applied with a $5 \mathrm{~mm}$ diameter round piston on the occlusal cuspal inclines at $1 \mathrm{~Hz}$ frequency.

\section{Microtensile bond strength evaluation}

The teeth were sectioned with a microtome (Leica SP 1600, Germany) using a diamond disc to produce dimensions of $0.9 \pm 0.1 \mathrm{~mm}^{2}$ thick beam shaped resin-dentin blocks. A total of 160 sections were obtained, i.e., two sections (mesial and distal) from each tooth. The specimens were attached to a custom-made jig with cyanoacrylate glue, and bond strength evaluation was done using a universal testing machine (Autograph, Shimadzu Inc, USA). The tensile load at which the fracture occurred was recorded in units of megapascals. The debonded specimens were examined under a scanning electron microscope (Hitachi, Tokyo, Japan) and the fracture patterns (adhesive, cohesive, or mixed) were assessed by taking photomicrographs at 200X magnification.

\section{Statistical analysis}

All the $\mu$ TBS values recorded in megapascals (MPa) were subjected to statistical analysis using software (SPSS 22.0, IBM, Armonk, NY). A one-way analysis of variance (ANOVA) was used to compare the tensile bond strength among groups. To compare the mean bond strength between two different groups, an independent sample t-test was used. Pair-wise comparisons among the groups were performed by using Tukey multiple post-hoc tests. Statistical analysis was performed at the $95 \%$ level of confidence, with the significance level established at $\mathrm{P} \leqslant 0.05$.

\section{Results}

The mean bond strength values of total-etch and self-etch adhesives to discolored amalgam replaced dentin were significantly lower $(\mathrm{p}<0.001)$ than those to freshly prepared dentin in the same teeth. The etch-andrinse (ER) adhesives exhibited statistically higher bond strength values to both types of dentin substrates tested as compared to self-etching (SE) adhesives $(\mathrm{p}<0.001)$ (Table 2). 


\section{Cureus}

\begin{tabular}{|c|c|c|c|c|}
\hline Groups & $\begin{array}{l}\text { Freshly placed composite with etch-and-rinse } \\
\text { adhesive }\end{array}$ & $\begin{array}{l}\text { Freshly placed composite with self-etch } \\
\text { adhesive }\end{array}$ & $\begin{array}{l}\text { Replaced amalgam with etch-and-rinse } \\
\text { adhesive }\end{array}$ & $\begin{array}{l}\text { Replaced amalgam with self-etch } \\
\text { adhesive }\end{array}$ \\
\hline Mean & 43.72 & 33.56 & 34.68 & 23.74 \\
\hline SD & 5.37 & 4.63 & 4.48 & 4.31 \\
\hline $\begin{array}{l}\text { Freshly placed composite with etch-and- } \\
\text { rinse adhesive }\end{array}$ & - & 60.001* & $00^{* *}$ & 01* \\
\hline $\begin{array}{l}\text { Freshly placed composite with self-etch } \\
\text { achesive }\end{array}$ & $P<0.001^{*}+1,1$ & - & $P=0.7168$ & $P<0.001$ \\
\hline $\begin{array}{l}\text { Replaced amalgam with etch-and-rinse } \\
\text { achesive }\end{array}$ & 201* & 的 & - & $1^{*}$ \\
\hline Replaced amalgam with se & $P<0.0011^{*}<>$ & $P<0.0011^{*}>0$ & $P<0.001^{*}<>>1$ & $\cdot$ \\
\hline
\end{tabular}

TABLE 2: Comparison of mean microtensile bond strength values in MPa by Tukey multiple posthoc test

MPa: megapascal

The microtensile bond strength of freshly cut dentin with SE adhesive and amalgam replaced dentin with ER adhesive were not statistically different $(\mathrm{p}=0.7168$ ). No significant difference was observed in the mode of failure patterns among the specimens bonded with two different adhesives to different dentin substrates. Overall adhesive failures were more, and mixed failure mode was observed in fewer samples (Figure 1). The highest percentage of adhesive failures were seen in amalgam replaced specimens that were bonded with self-etch adhesive.

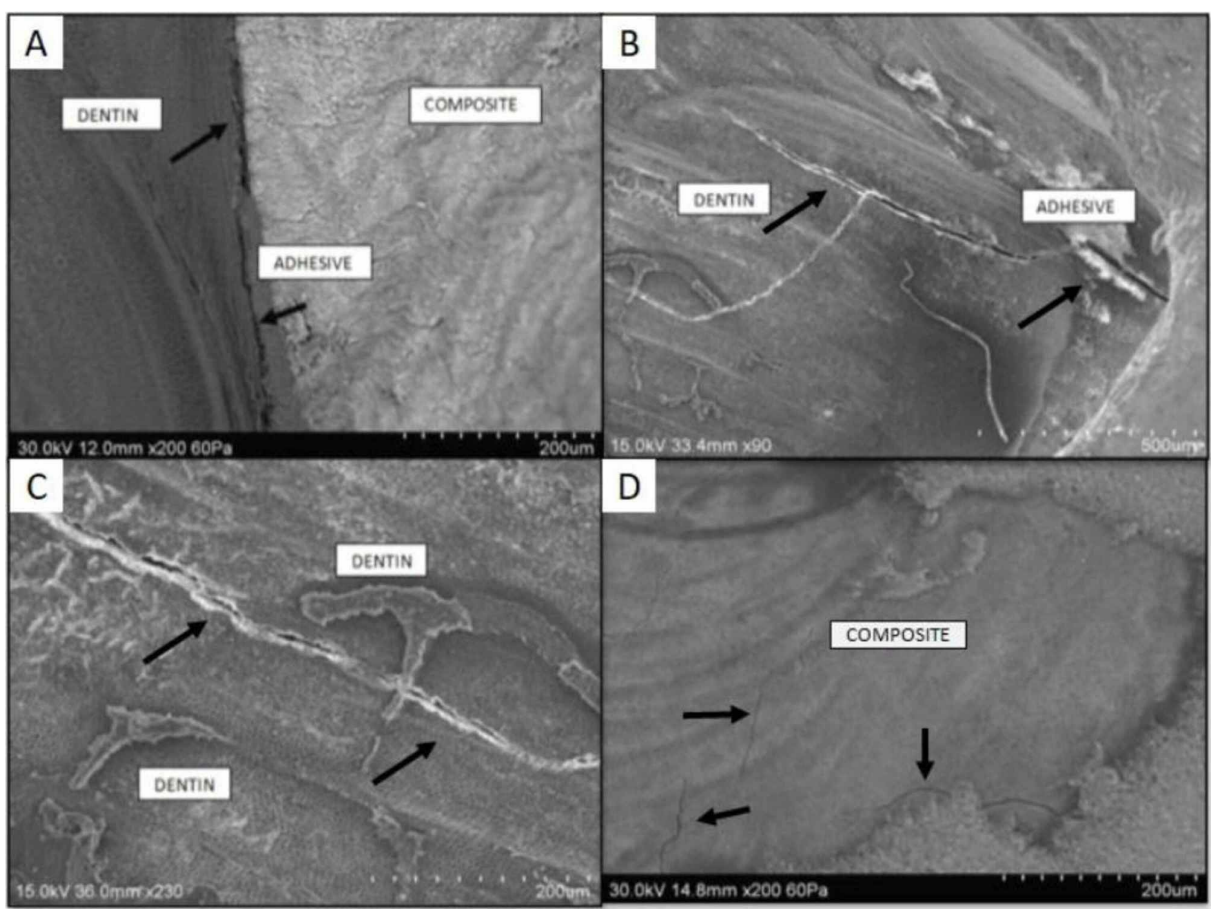

FIGURE 1: Scanning electron microscopic images of specimens showing failure modes

A) Adhesive failure at dentin and composite interface; B) Mixed failure - cohesive failure within the dentin and adhesive failure at the dentin and adhesive interface; C) Cohesive failure within the dentin; D) Cohesive failure within the composite

\section{Discussion}


Although the microtensile bond strength $(\mu \mathrm{TBS})$ test is technique sensitive and complicated, being conservative is the major advantage as more specimens can be prepared from a single tooth. Also, we can obtain bond strength values from a relatively small sample, i.e., from less than one $\mathrm{mm}^{2}$ cross-sectional area [12-14].

With trituration of the silver alloy and mercury, a matrix structure of $\mathrm{Ag}_{2} \mathrm{Hg}_{3}\left(\gamma_{1}\right.$ phase $)$ and $\mathrm{Sn}_{8} \mathrm{Hg}\left(\gamma_{2}\right.$ phase) forms around alloy particles $\mathrm{Ag}_{3} \mathrm{Sn}$ ( $\gamma$ phase). The $\gamma_{2}$ phase is the highly corroded phase and mechanically the weakest phase in conventional amalgams. The $\gamma_{2}$ phase causes oxidation of Sn and reduces the $\mathrm{pH}$, promoting the acidic environment allowing migration of Sn from amalgam to the dentin restorative interface and getting deposited $[2,15]$. As the clinician will not be aware of the type of amalgam that was used before while replacing it with composite restoration, to test the worst possible substrate for bonding, conventional amalgam was used in this study.

In an attempt to optimize the infiltration of hydrophobic resins into acid-etched dentin, the ethanol wet bonding technique has been introduced. The research has established that ethanol is the better solvent in the etch-and-rinse primer to produce long-lasting bond strength [16]. The tetric N-bond (two-step) totaletch adhesive was selected in this study for that reason. The tetric N-bond (single step) self-etch adhesive used is a non-rinse adhesive. These adhesives resemble the etch-and-rinse systems by forming a hybrid layer deeper and the dissolved calcium phosphates are embedded within the hybrid layer, without being washed away [17].

Tetric N-Ceram bulk-fill has an increased translucency with an effective depth of cure. In addition to the camphorquinone/amine initiator system, Ivocerin is added for better polymerization. Ivocerin is a germanium-based initiator that has high photocuring activity due to its greater absorption between the 400 and $500 \mathrm{~nm}$ wavelengths and forms two free radicals to initiate polymerization [18].

The degradation patterns observed within the hybrid layer are of two types, i.e., loss of resin from interfibrillar spaces and the disorganization of unprotected collagen fibrils [18]. To simulate the intra-oral aging effects, thermo-mechanical cyclic loading was applied to the restored teeth that might correspond to one year of intra-oral functioning $[10,14,19]$.

The results of the present study support the hypothesis that the microtensile bond strengths of both ER and SE adhesives to discolored dentin after the removal of amalgam restorations were lower than that of freshly prepared dentin. This finding was correlating with several previous study results $[2,15,20]$. It was hypothesized that corrosive amalgam products cause the precipitation of plasma proteins into the dentinal fluid and interfere with smear layer removal, rendering the discolored dentin less etchable than freshly cut dentin. Consequently, the discolored dentin under replaced amalgam restoration is less permeable and reduces the adhesive resin monomer infiltration [15].

Ghavamnasiri et al. recommended a $0.5 \mathrm{~mm}$ extension of the cavity preparation after the removal of amalgam, to improve the adaptation of composite restorations [11]. They reported similar microleakage values after the removal of discolored dentin beneath the amalgam restoration to that of freshly done composite restorations. In contrast to these findings, Redwan et al. found no difference in microleakage when previously restored amalgam and freshly prepared dentin were tested [1]. The EDX analysis of their study revealed no metal elements in dentin beneath amalgam, and only elements of calcium and phosphorous were identified. Though metal ions did not penetrate the discolored dentin in their study, as compared to freshly prepared dentin, amalgam replaced dentin showed more microleakage, though it was not significant.

The results of the current study revealed lower bond strength values for tetric N self-etch adhesive to both the dentin substrates tested as compared to the total-etch adhesive. With acid-etching, dentin activates and releases matrix metalloproteinases (MMPs), which may partially disintegrate non-resin impregnated collagen within the hybrid layer. In the etch-and-rinse process, phosphoric acid rapidly denatures the MMP activity reducing the gelatinolytic activity. When the $\mathrm{pH}$ values reach near zero, whatever gelatinolytic activity is exposed by acid-etching seems to be destroyed [21]. On the other hand, with self-etch adhesives having $\mathrm{pH} \geqslant 2$ may activate MMPs at a higher level but may not be acidic enough to denature MMPs [8]. Contrary to this finding, Harnirattisai et al. found a significantly higher bond strength to normal dentin for a Clearfil SE Bond (Kuraray America, Inc., New York) as compared to that of a single bond adhesive [2]. A possible explanation for the higher bond strength to SE adhesive in their study might be due to the fact that thermal/mechanical treatment for the samples was not done. They reported that bond strength for discolored dentin was not statistically different between the two adhesive systems tested.

Lower $\mu$ TBS for SE adhesives in this study could be attributed to the thinner hybrid layer formation (0.5 to 1 $\mu \mathrm{m})$ by this adhesive that could not resist the stresses developed during thermal and mechanical cycling [22]. Studies have reported the vulnerability of single-step self-etch adhesives for phase separation due to the droplets or blisters formed at the adhesive-tooth substrate interface. Apart from that, single-step SE adhesives contain a higher amount of water, which is essential for ionization, and that purportedly reduces 
the conversion rate of the resin [23]. Total-etch adhesive tested in the study have ethanol as a secondary solvent. Ethanol having high solubility and osmotic pressure helps displace water and allow the monomers penetration into the opened dentinal tubules [17]. This might be the reason for attaining higher $\mu$ TBS values for ER adhesive, as thermo-mechanical stresses will be distributed along the hybrid layer.

The failure mode analysis revealed more of adhesive failures independent of the adhesive system used. This finding is similar to other study results, which reported decreased bond strength with increased adhesive failure after thermocycling [14]. Mitsui et al. reported that with an increased number of thermal/mechanical cycles, the number of mixed failures increases [23]. Due to the partial degradation of resin-dentin interface with aging, mixed failure mode exhibits some cohesive and some adhesive failures [24].

Clinical trials are ideal for the evaluation of dental restorations. An in-vivo study evaluated the longevity of extensive cuspal replacement resin composite restorations that were done upon removal of existing amalgam restorations. They reported that the dentin exposed under earlier amalgam restoration does not impair adhesion of composite resin as they found a good survival rate (96.6\%) after 3.5 years with a $0.9 \%$ annual failure rate [25].

\section{Conclusions}

The results of this in vitro study provides evidence that etch-and-rinse adhesives provide a higher bond strength to normal dentin and discolored dentin after amalgam removal. Discolored dentin beneath the amalgam restoration decreases the bond strength of an adhesive restoration. Though a single-step SE is desirable in a clinical situation, having acids with hydrophilic and hydrophobic monomers in a single solution might compromise the function of individual constituents. No significant difference was observed in the failure pattern modes among the specimens bonded with two different adhesives to different dentin substrates. Overall adhesive failures are more, and mixed failure mode was observed in a smaller number of samples.

\section{Additional Information \\ Disclosures}

Human subjects: All authors have confirmed that this study did not involve human participants or tissue. Animal subjects: All authors have confirmed that this study did not involve animal subjects or tissue. Conflicts of interest: In compliance with the ICMJE uniform disclosure form, all authors declare the following: Payment/services info: All authors have declared that no financial support was received from any organization for the submitted work. Financial relationships: All authors have declared that they have no financial relationships at present or within the previous three years with any organizations that might have an interest in the submitted work. Other relationships: All authors have declared that there are no other relationships or activities that could appear to have influenced the submitted work.

\section{References}

1. Redwan H, Bardwell DN, Ali A, Finkelman M, Khayat S, Weber HP: Composite replacement of amalgam restoration versus freshly cut dentin: an in vitro microleakage comparison. Oper Dent. 2016, 41:73-82. 10.2341/14-278-L

2. Harnirattisai C, Senawongse P, Tagami J: Micro-tensile bond strengths of two adhesive resins to discolored dentin after amalgam removal. J Dent Res. 2007, 86:232-236. 10.1177/154405910708600307

3. Marek M: Interactions between dental amalgams and the oral environment. Adv Dent Res. 1992, 6:100-109. $10.1177 / 08959374920060010101$

4. Isolan CP, Sarkis-Onofre R, Lima GS, Moraes RR: Bonding to sound and caries affected dentin: a systematic review and meta-analysis. J Adhes Dent. 2018, 20:7-18. 10.3290/j.jad.a39775

5. Mohan B, Kandaswamy D: A confocal microscope evaluation of resin dentin interface using adhesive systems with three different solvents bonded to dry and moist dentin: an in vitro study. Quintessence Int. 2005, 36:511-521.

6. Moszner N, Salz U, Zimmermann J: Chemical aspects of self-etching enamel-dentin adhesives: a systematic review. Dent Mater. 2005, 21:895-910. 10.1016/j.dental.2005.05.001

7. Van Meerbeek B, Van Landuyt K, De Munck J, et al.: Technique-sensitivity of contemporary adhesives . Dent Mater. 2005, 24:1-13. 10.4012/dmj.24.1

8. De Munck J, Mine A, Van den Steen PE, Van Landuyt KL, Poitevin A, Opdenakker G, Van Meerbeek B: Enzymatic degradation of adhesive-dentin interfaces produced by mild self-etch adhesives . Eur J Oral Sci. 2010, 118:494-501. 10.1111/j.1600-0722.2010.00758.x

9. Pashley DH, Carvalho RM, Sano H, et al.: The microtensile bond test: a review . J Adhes Dent. 1999, 1:299309.

10. Schmid-Schwap M, Graf A, Preinerstorfer A, Watts DC, Piehslinger E, Schedle A: Microleakage after thermocycling of cemented crowns--a meta-analysis. Dent Mater. 2011, 27:855-869. 10.1016/j.dental.2011.05.002

11. Ghavamnasiri M, Motamed-Sanaye V, Chasteen J, Ameri H, Hajizadeh H, Khashyarmanesh Z: Energy dispersive $\mathrm{x}$-ray analysis of corrosion products in nondiscolored dentin and a dye-extraction study of class II composite restorations following amalgam removal. Quintessence Int. 2012, 43:325-332.

12. Nakornchai S, Harnirattisai C, Surarit R, Thiradilok S: Microtensile bond strength of a total-etching versus self-etching adhesive to caries-affected and intact dentin in primary teeth. J Am Dent Assoc. 2005, 136:477- 
483. 10.14219/jada.archive.2005.0203

13. Omar H, El-Badrawy W, El-Mowafy O, Atta O, Saleem B: Microtensile bond strength of resin composite bonded to caries-affected dentin with three adhesives. Oper Dent. 2007, 32:24-30. 10.2341/06-2

14. Xie C, Han Y, Zhao XY, Wang ZY, He HM: Microtensile bond strength of one- and two-step self-etching adhesives on sclerotic dentin: the effects of thermocycling. Oper Dent. 2010, 35:547-555. 10.2341/10-025-I

15. Scholtanus JD, Ozcan M, Huysmans MC: Penetration of amalgam constituents into dentine . J Dent. 2009, 37:366-373. 10.1016/j.jdent.2009.01.009

16. Gupta A, Tavane P, Gupta PK, et al.: Evaluation of microleakage with total etch, self etch and universal adhesive systems in class V restorations: an in vitro study. J Clin Diagn Res. 2017, 11:53-56. 10.7860/JCDR/2017/24907.9680

17. Knobloch LA, Gailey D, Azer S, Johnston WM, Clelland N, Kerby RE: Bond strengths of one and two-step self-etch adhesive systems. J Prosthet Dent. 2007, 97:216-222. 10.1016/j.prosdent.2007.02.013

18. Ilie N, Stark K: Curing behaviour of high-viscosity bulk-fill composites. J Dent. 2014, 42:977-985. 10.1016/j.jdent.2014.05.012

19. Armstrong S, Breschi L, Özcan M, Pfefferkorn F, Ferrari M, Van Meerbeek B: Academy of dental materials guidance on in vitro testing of dental composite bonding effectiveness to dentin/enamel using micro-tensile bond strength $(\mu \mathrm{TBS})$ approach. Dent Mater. 2017, 33:133-143. 10.1016/j.dental.2016.11.015

20. Frankenberger R, Garcia-Godoy F, Murray PE, Feilzer AJ, Krämer N: Risk aspects of dental restoratives: from amalgam to tooth colored materials. World J Stomatol. 2013, 2:1-11. 10.5321/wjs.v2.i1.1

21. Breschi L, Maravic T, Cunha SR, et al.: Dentin bonding systems: from dentin collagen structure to bond preservation and clinical applications. Dent Mater. 2018, 34:78-96. 10.1016/j.dental.2017.11.005

22. Takamizawa T, Barkmeier WW, Tsujimoto A, DD Scheidel, Erickson RL, Latta MA, Miyazaki M: Effect of phosphoric acid pre-etching on fatigue limits of self-etching adhesives. Oper Dent. 2015, 40:379-395. 10.2341/13-252-L

23. Mitsui FH, Peris AR, Cavalcanti AN, Marchi GM, Pimenta LA: Influence of thermal and mechanical load cycling on microtensile bond strengths of total and self-etching adhesive systems. Oper Dent. 2006, 31:240247. 10.2341/05-20

24. Bedran-de-Castro AK, Pereira PN, Pimenta LA, Thompson JY: Effect of thermal and mechanical load cycling on microtensile bond strength of a total-etch adhesive system. Oper Dent. 2004, 29:150-156.

25. Scholtanus JD, Ozcan M: Clinical longevity of extensive direct composite restorations in amalgam replacement: up to 3.5 years follow-up. J Dent. 2014, 42:1404-1410. 10.1016/j.jdent.2014.06.008 